\title{
1 Reconstruction of recent sea-level change using testate amoebae
}

2

3 Dan J. Charman ${ }^{1}$, W. Roland Gehrels ${ }^{2}$, Claire Manning ${ }^{2}$ and Charu Sharma ${ }^{3}$

4

$5{ }^{1}$ School of Geography, University of Exeter, Exeter, EX4 4RJ, United Kingdom

$6{ }^{2}$ School of Geography, Earth and Environmental Sciences, University of Plymouth, Plymouth,

7 Devon, PL4 8AA, United Kingdom

$8 \quad{ }^{3}$ School of Marine Science and Engineering, University of Plymouth, Plymouth, Devon, PL4

9 8AA, United Kingdom

10

$11{ }^{*}$ Correspondence: d.j.charman@exeter.ac.uk, +44 1392 262435, Fax: +44 1392263342

12 


\section{Abstract}

Proxy-based sea-level reconstructions place the instrumentally observed rates of recent sealevel rise in a longer term context by providing data that extend the instrumental sea-level record into past centuries. This paper presents the first sea-level reconstructions based on analyses of testate amoebae, to test their capability to improve the precision of past sea-level reconstructions. We used sample preparation methods commonly used in peatland studies, but applied a modified sample preparation based on a weak alkali treatment to improve the efficiency of the counting process. We present two reconstructions for the past 100 years from sites in Maine (USA) and Nova Scotia (Canada) based on short cores from salt marshes and modern training data from North America and the United Kingdom. These are compared with tide-gauge records and reconstructions based on foraminifera from the same cores. The reconstruction from the Chezzetcook marsh (Nova Scotia) shows good agreement with both the tide-gauge and the foraminifera-based reconstruction and is insensitive to the modern training set and underlying transfer function model. The Wells (Maine) reconstruction is also consistent with the tide-gauge record and foraminifera-based reconstruction, but shows greater variability depending on methodology applied. The precision of testate amoebae-based reconstructions is higher than those for foraminifera, but further work on surface samples is needed to improve the accuracy of reconstructed values. The UK data perform well in predicting known elevations of North American surface samples, and sea-level reconstructions based on the UK transfer function are very similar to those based on the North American data, suggesting the methodology is robust across large geographical areas. We conclude that testate amoebae have the potential to provide robust, higher precision sea-level reconstructions for the past few centuries if modern transfer functions are improved and core sites are located within the main zone of testate amoebae occurrence on the saltmarsh. 


\section{Introduction}

Sea-level change is one of the most important aspects of future global change and understanding the causes, rates and geographical and temporal variability of sea level is crucial to improving predictions of $21^{\text {st }}$ century sea-level rise. Measurements and reconstructions of past sea level play an important part in improving understanding of sealevel change (Bindoff et al., 2007). Tide-gauge records and satellite data provide high temporal resolution data, but the temporal and spatial coverage of these records is limited. Reconstructions of sea-level change over the past few millennia are therefore critical to understanding the dynamics of sea-level change and there are a growing number of reconstructions for locations around the world (e.g. Varekamp et al., 1992; van de Plassche et al., 1998; Donnelly et al., 2004; Gehrels et al., 2002; 2005; 2008). Recent research has used high temporal resolution records to show that current rates of sea-level rise are two to three times faster than longer terms rates over previous centuries (Gehrels et al., 2005). Whilst this longer term context for individual locations is important, it does not necessarily help test hypotheses concerning the causes and sources of the recent acceleration in sealevel rise, unless an appropriate spatial and temporal network of reconstructions exists. Adequate spatial and temporal coverage of sea-level change over the last few hundred years can only be provided by palaeoenvironmental records, due to the spatial bias in tide gauge records to the northern hemisphere.

The most detailed and precise late Holocene sea-level reconstructions are based on the use of salt-marsh foraminifera as sea-level indicators. Statistical analyses indicate that in most locations the precision of sea-level positions reconstructed from foraminifera is on the order of $\pm 20 \mathrm{~cm}$ (Gehrels, 2000; Edwards and Horton, 2000; Horton et al., 1999a; 1999b) while only along microtidal coastlines, such as the Atlantic coast of Nova Scotia, Canada, the precision is better than $\pm 10 \mathrm{~cm}$ (Gehrels et al., 2005). In most mid-latitude North Atlantic locations the rise of sea level in the past century has been around 10-20 cm (Holgate, 2007; Woodworth et al., 2008). If an attempt is made to detect the onset of this recent rapid rise it is therefore desirable to use sea-level indicators that have higher precision than those offered 
by foraminifera. Diatoms improve precision in some contexts but testate amoebae appear to have particular potential as high-precision indicators in saltmarsh sediments with tightly constrained zonation in relation to elevation in the upper marsh and supra-tidal zones (Charman et al., 1998; Gehrels et al, 2001; Charman et al., 2002). However, apart from an initial assessment of samples from a range of sedimentary contexts (Roe et al., 2002) there have been no attempts to use testate amoebae to develop and test high resolution records of sea-level change.

This paper reports the results of testate amoebae analysis on two saltmarsh cores from the Atlantic coast of North America to demonstrate the use of testate amoebae as highprecision sea-level indicators capable of detecting fluctuations of the order of $\pm 10 \mathrm{~cm}$ over multi-decadal to centennial timescales. Our reconstructions are assessed against nearby tide-gauge data and published sea-level reconstructions based on foraminifera. We also suggest an improved preparation procedure that overcomes some of the difficulties associated with counting low concentrations of testate amoebae in organic silty sediments that are typical of high marsh settings (Roe et al., 2002).

\section{Testate amoebae as sea-level indicators} Testate amoebae (or 'thecamoebians') are a group of test-forming protozoa some of which are related to foraminifera. They are known to be good indicators of hydrological conditions in peatlands (e.g., Tolonen, 1986; Charman et al., 2006). Testate amoebae have also been reported in salt-marsh environments (e.g., Scott et al., 1991; 1995a) in samples prepared for foraminiferal analyses, but only in low numbers and low diversity in the size fraction 63-500 $\mu \mathrm{m}$. We have collected testate amoebae from surface sediments in salt marshes in the UK (Charman et al., 1998; 2000a; 2002; Gehrels et al., 2001; Roe et al., 2002) and along the eastern seaboard of North America (Gehrels et al., 2006). In these investigations we have applied techniques commonly used in peatland studies (Hendon and Charman, 1997) and examined the fraction between 15 and $63 \mu \mathrm{m}$ in addition to the $63-500 \mu \mathrm{m}$ fraction. Our results indicate that small testate amoebae $(<63 \mu \mathrm{m})$ are much more abundant and diverse 
in salt-marsh sediments than the larger testate amoebae $(>63 \mu \mathrm{m})$. The vertical distribution of testate amoebae is distinctly zoned on the surface of salt marshes, and shows a stronger zonation than that of diatoms and foraminifera in the highest levels of marshes (Gehrels et al., 2001). Testate amoebae can be found as low as the level of mean high spring tide but their vertical extent reaches upward into areas well above the highest limit of foraminifera. Based on quantitative analyses of modern datasets we have concluded that testate amoebae may be capable of resolving sea-level positions with a precision perhaps as low as $\pm 4 \mathrm{~cm}$ in microtidal sites, provided that fossil testate amoebae are present and well preserved in subsurface sediments (Gehrels et al., 2006). This study represents the first systematic attempt to use fossil testate amoebae to reconstruct recent sea-level change.

\section{Site descriptions and previous work}

We sampled cores from two previously studied sites in Maine and Nova Scotia (Figure 1). The Webhannet marsh in Wells, Maine $\left(43^{\circ} 18^{\prime} \mathrm{N}, 70^{\circ} 34^{\prime} \mathrm{W}\right)$ is a backbarrier marsh along the Wells embayment in southwestern Maine (USA). The marsh is connected to the Gulf of Maine by a flood-dominated tidal inlet and the mean tidal range in the marsh is $2.64 \mathrm{~m}$ (Gehrels, 1994). The sea-level history has previously been determined from salt-marsh plant fossils (Belknap et al., 1989) and foraminifera (Kelley et al.,1995; Gehrels et al., 1996; 2002). The core selected for the present study is core FS-1 from the high marsh zone where Spartina patens is the dominant plant cover. This core was first analysed for foraminifera by Gehrels et al. (2002) and formed the basis for a detailed sea-level chronology spanning the past 1200 years. The sea-level curve for Wells compared well with a curve produced for Machiasport in eastern Maine and is therefore interpreted to be representative for the Gulf of Maine. In the past 100-200 years the Gulf of Maine has experienced 0.3-0.4 m of relative sea-level rise, the fastest rise in the past millennium. Gehrels et al. (2002) suggested that sea-level rise may have been slow in the middle of the $19^{\text {th }}$ century, but the precision of their reconstruction precluded a clear distinction between pre- and post-industrial rates of sealevel rise. 
125 micro- to mesotidal with a tidal range of $2.14 \mathrm{~m}$ at the mouth of the inlet. Tidal range is

126 reduced to $1.86 \mathrm{~m}$ at the West Head location where core CZ-25 is located in the high marsh

127 zone dominated by Spartina patens (Gehrels et al., 2005). Chezzetcook Inlet has been the

128 site of previous Holocene sea-level studies, including those by Scott (1977), Scott et al.

129 (1987; 1995b) and Gehrels et al. (2004; 2005). Gehrels et al. (2005) established a high-

130 resolution sea-level reconstruction for the last 1000 years based on foraminifera and showed

131 a doubling of the rate of sea-level rise, from $1.6 \mathrm{~mm} \mathrm{yr}^{-1}$ to $3.2 \mathrm{~mm} \mathrm{yr}^{-1}$, shortly after c. AD 1321900.

134 Laboratory methods

135 Standard preparations for testate amoebae samples are water-based sieving to separate the

$136 \quad 15-300 \mu \mathrm{m}$ fraction for counting at 100-1000x magnification under a light microscope

137 (Charman et al., 2000b). However, in fossil and some surface samples, this process retains a

138 large amount of silt-sized organic remains that can obscure the tests, rendering samples

139 difficult or impossible to count to totals that are appropriate for statistical analysis. Previous

140 assessments on terrestrial peat have shown that typical pollen preparation processes and

141 other chemical treatments damage or destroy tests and so are not generally used. However,

142 low strength alkali treatment prior to sieving can remove organic aggregates. Although there

143 is some alteration of structure, tests are not destroyed and can still be identified (Hendon and

144 Charman, 1997). We used a modified procedure of Hendon and Charman (1997), including

145 pre-treatment with $5 \% \mathrm{KOH}$ to eliminate unwanted detritus. We compared counts from eight

146 test samples from the Wells core, with and without $\mathrm{KOH}$ treatment to assess the effects on

147 test numbers and concentrations. Following this preliminary test, we applied the same

148 preparation process to all fossil samples.

149 Samples of $0.2-0.5 \mathrm{ml}$ from $1 \mathrm{~cm}$ thick slices were collected from the cores and

150 weighed. One tablet of Lycopodium clavatum L. was added as an exotic marker (Stockmarr,

151 1971). Samples were boiled in $100 \mathrm{ml}$ distilled water for 5-10 minutes, stirred occasionally to 
152 aid disaggregation and left soaking overnight. The next day, samples were sieved and the

153 fraction of $15-300 \mu \mathrm{m}$ was retained for analysis. A $4 \mathrm{ml}$ solution of $5 \% \mathrm{KOH}$ was added and 154 samples were warmed at approximately $80^{\circ} \mathrm{C}$ for $1-2$ minutes and sieved again at $15 \mu \mathrm{m}$ to 155 remove more fine detritus. Finally, samples were mounted in glycerol or water onto a 156 microscope slide with a $22 \times 40 \mathrm{~mm}$ cover slip sealed with nail varnish. In the initial test of

$157 \mathrm{KOH}$ treatment, testate amoebae were counted until 150 Lycopodium spores had been 158 counted. In the full counts of fossil samples, at least 50 tests were counted. The time-

159 consuming nature of the counting procedure precluded the counting of more specimens, but 160 the number of 50 individuals is sufficient in the absence of rare taxa (those that occur in very 161 low abundances of perhaps $<5 \%$; Patterson and Fishbein, 1991). Data from some samples 162 with $<50$ specimens are also included in the results section but these data are not used for 163 transfer functions or sea-level reconstructions.

164 A series of transfer functions based on surface samples of testate amoebae were 165 applied to the fossil data using the program C2 (Juggins, 2003). Two main data sets were 166 used for this. First, we tested several different transfer functions based on data from two 167 marshes in the region, consisting of 29 surface samples from the Little River Marsh 168 (approximately $4 \mathrm{~km}$ from the Wells core site) and the Little Dipper Harbour marsh in New 169 Brunswick (Gehrels et al., 2006). These data sets are illustrated in Figure 2 as taxon 170 abundance plotted against surface elevation and show the strong zonation of taxa along the 171 tidal gradient. We also applied a local transfer function to the Wells data based only on the 17217 samples from the Little River Marsh, although this has the disadvantage that sample 173 numbers are too low to generate sample specific error estimates. Second, we tested a 174 similar series of transfer functions based on modern data from the United Kingdom 175 (Charman et al., 2002) to test whether taxon-environment relationships are robust across the 176 North Atlantic region. If modern relationships are spatially robust, it is more likely that the 177 transfer functions are also temporally robust. To assess this, the best performing transfer 178 function in cross validation of the UK data was applied to the modern North American 179 samples as well as to the fossil samples. In order to combine data from sites with different 
180 tidal ranges, elevation data were normalised in relation to the difference between mean tidal

181 level (MTL) and highest astronomical tide (HAT).

182 The chronologies for the cores were based on radiocarbon, ${ }^{210} \mathrm{~Pb},{ }^{137} \mathrm{Cs},{ }^{207} \mathrm{~Pb} /{ }^{206} \mathrm{~Pb}$ ratios 183 and pollen analyses (Gehrels et al., 2002; 2005). For Chezzetcook, the age-depth model is 184 based on ${ }^{210} \mathrm{~Pb}$ ages for the upper part of the profile, cross-checked against ${ }^{207} \mathrm{~Pb}:{ }^{206} \mathrm{~Pb}$ ratios 185 and ${ }^{137} \mathrm{Cs}$, and extrapolated for ages prior to $\mathrm{C}$. AD 1890 to a pollen marker at $\mathrm{AD} 1780 \pm 20$

186 years (Gehrels et al., 2005, Figure 8b). For Wells, the chronology is based on ${ }^{210} \mathrm{~Pb}$ cross 187 checked against ${ }^{137} \mathrm{Cs}$ and extrapolated to a pollen marker at AD 1760 (Gehrels et al', 2002,

188 Figure 2). The samples used for testate amoebae analysis date almost entirely from the 189 sections of the cores dated by ${ }^{210} \mathrm{~Pb}$ to post AD 1900 , supported by ${ }^{137} \mathrm{Cs}$ and ${ }^{207} \mathrm{~Pb}:{ }^{206} \mathrm{~Pb}$

190 ratios. For the Wells core, we also tested for the presence of spheroidal carbonaceous 191 particles (SCPs), markers for industrial pollution found widely in lake and peat sediments but 192 not reported from saltmarsh deposits (Rose, 2001).

\section{Results}

\section{Effect of $\mathrm{KOH}$ treatment}

A total of 60 tests were counted in the eight samples prepared by standard water-based techniques (Table 1). Both the count (29) and the concentration $\left(56.4 \mathrm{mg}^{-1}\right)$ were highest in

198 the sample from 8-9 cm depth, with other samples having counts between 1 and 8 tests,

199 representing concentrations of 4.9-18.1 tests $\mathrm{mg}^{-1}$. Counts were higher overall in the samples 200 treated with $\mathrm{KOH}$ (71 tests counted) and concentrations were also increased in the samples 201 from $32 \mathrm{~cm}$ and above where counts were highest. Deeper samples had very low counts $202(<10)$ and concentrations $\left(<10 \mathrm{mg}^{-1}\right)$ in both treatments and generally showed reduced counts and concentrations following $\mathrm{KOH}$ treatment. The assemblage composition of the

204 samples with counts $>10$ is very similar between treatments with most of the same dominant 205 taxa present. Furthermore, although we did not quantify counting effort, the slides were 206 generally clearer with better dispersal of material and reduced amounts of fine organic 207 material visible. We conclude that the weak $5 \% \mathrm{KOH}$ treatment improves overall quality of 
slides without selective effects on the assemblage. Increased concentrations in the $\mathrm{KOH}$

209 treatment suggest that tests are hidden by detritus in the water-based treatment. Although

210 the numbers and range of samples and tests counted was not adequate to be conclusive, the

211 results also indicate that damage to tests was not significant enough to prevent detection and

212 identification of all taxa. Hendon and Charman (1997) also reported increased concentrations

213 of tests following a stronger $10 \% \mathrm{KOH}$ treatment, but found significant damage to tests. Our

214 results suggest a lower concentration of $\mathrm{KOH}$ retains the benefit of reduced detritus while

215 avoiding problems of test damage. This is an area still requiring further work and a

216 systematic experiment to determine optimum combinations of $\mathrm{KOH}$ concentration,

217 temperature and length of treatment.I It seems likely that weak alkali treatments of

218 problematic samples with low test concentrations improves counting efficiency and increases

219 the numbers of samples from which data can be obtained, but we would not advocate using

220 this process in the absence of some evaluation of its impact on specific samples and

221 assemblages.

\section{Modern assemblages and transfer functions}

224 North American data

225 The modern assemblages (Figure 2) show a strong zonation from elevations below mean

226 higher high water (MHHW) extending to well above highest astronomical tide (HAT) and

227 zonation is similar for both sites. A full discussion of the modern assemblages is given by

228 Gehrels et al. (2006), but we include these data here to allow comparison with the fossil

229 assemblages. The highest occurrence of foraminifera is at (Little River) or just below (Ltitle

230 Dipper) HAT, where dominant testate amoebae are Centropyxis cassis type, Euglypha

231 rotunda type and Tracheleuglypha dentata. . The lowewrmost samples are dominated by

232 taxa such as Digglugia pristis type and Centropyxis platystoma type 
234 Transfer functions based on weighted averaging performed best in leave-one-out cross

235 validation (Table 2), with no improvement from using a partial-least-squares version of

236 weighted averaging. A linear-based partial-least-squares model performed similarly and two

237 approaches based on modern analogue matching were significantly worse. The weighted

238 average model based on classic deshrinking (WA_Cla) had the highest $r^{2}(0.85)$, lowest

239 maximum bias and low RMSEP and was applied to the fossil data sets. For comparison with

240 a tolerance downweighted model, which is potentially more stable in reconstructions, the

241 WAT_Cla model was also applied.

UK data

244 The UK data set consists of modern samples from three sites (Taf estuary, S.Wales; Erme 245 estuary, Devon; Brancaster marsh, Norfolk). Previously these data were used to examine a 246 variety of relationships between testate amoebae and environmental conditions (Charman et 247 al., 2002) and to test the potential of multi-proxy microfossil data for sea-level reconstructions 248 (Gehrels et al., 2001). Here we test the ability of these data to estimate the known elevation 249 of the modern samples from the North American marshes in order assess the applicability of 250 transfer functions over very wide geographical regions..

252 The transfer functions for the UK data suggest very good performance of some models 253 (Table 3). In particular, the linear partial least squares (PLS) model produced very high $\mathrm{r}^{2}$ 254 (0.99) and low RMSEP (0.012) values. The modern analogue technique also produced good 255 cross validation statistics $\left(r^{2}=0.61, R M S E P=0.063\right)$, but the residuals were systematically 256 biased with strong over-prediction in low elevation samples and under-prediction in high 257 elevation samples (plot not shown). The best performing weighted average model (WAT_Inv; 258 tolerance downweighted weighted average with inverse deshrinking) had a good $r^{2}(0.47)$ 259 and low RMSEP (0.074). Both the PLS and WAT_Inv models were applied to the US 260 samples to assess their applicability to North American data (Table 3, Figure 3).

261 Performance in terms of RMSEP (Table 3) was surprisingly good for both transfer functions, 
although both tended to show a systematic bias towards over prediction at low elevations and under-predictions at higher elevations (Figure 3a). This tendency was much more extreme for the PLS model.

Normalising the data to the height between MTL and HAT is necessary in order to take account of differing tidal range between sites for transfer-function development based on more than one site, but for reconstruction of past sea level, these values are converted back to actual elevation using the modern tidal range for the site concerned. It is assumed that tidal range remained unchanged, which is reasonable for reconstructions covering only the last 100 years. We therefore tested the ability of different transfer functions to estimate the actual elevation for the modern samples at the US sites, as an improved test of model performance (Figure 3b). The tendency of the PLS model to underestimate the difference in elevation between samples was even more marked here, whereas the WAT_Inv model either slightly under-estimated (Little River) or slightly over-estimated (Little Dipper) this difference. Although the PLS model shows consistently higher statistical performance in cross validation (Table 3) than the WAT_Inv model, the WAT_Inv model is therefore a much more robust model for reconstructions. In particular, the characteristics of the WAT_Inv model mean that it is much more likely to give accurate estimates of multi-decadal trends in reconstructions

280 from fossil samples, a key aim in high temporal resolution studies (e.g. Gehrels et al., 2002; $2812005 ; 2008)$. Both models systematically underestimate elevation for the Little Dipper site 282 and slightly overestimate elevation for the Little River marsh, suggesting the normalisation is not accurate, perhaps due to inaccuracy of the elevations for MTL and especially for HAT. The UK WAT_Inv model was applied to the Wells fossil data using a correction based on the average over-prediction for the Little River modern samples. No correction was applied to

286 Chezzetcook fossil samples, as no modern data were available to estimate the prediction 287 offset at this site.

\section{Sea-level reconstructions}


291 Tests were present in the top $19 \mathrm{~cm}$ of the Wells core, with only very low numbers below this

292 level (Figure 4, Table 1). Concentrations were up to 30,000 tests $\mathrm{g}^{-1}$, but were generally 293 much lower at 5-13,000 tests $\mathrm{g}^{-1}$ and only $1000-2500$ tests $\mathrm{g}^{-1}$ in the samples $13-16 \mathrm{~cm}$ 294 depth. Below $16 \mathrm{~cm}$ concentrations fell to $100-500$ tests $\mathrm{g}^{-1}$ and no tests were found in a 295 sample from $22-23 \mathrm{~cm}$ despite counting 200 Lycopodium spores. For the purposes of 296 comparison with tide-gauge data, we focused on the top part of the profile which is dated to 297 the $20^{\text {th }}$ century. Details of the chronological methods are given in Gehrels et al. (2002), but 298 for this site we also tested the use of SCPs for dating The SCP curve shows the first major 299 consistent presence of SCPs at about 12cm depth, dated to c. AD 1866 by extrapolating between the pollen marker and the lowermost reliable ${ }^{210} \mathrm{~Pb}$ ages. A mid- $19^{\text {th }}$ century age is 301 typical for the start of SCP curves in Europe, but this has not yet been established for North 302 America. Given the lack of sites with independently estimated ages for SCP curves, it is not 303 yet possible to use SCPs as an absolute age marker in this region. However, if adopted more 304 widely for sediment dating it would provide a valuable relative age marker and ultimately a 305 useful additional chronological tool for eastern North America.

306 In the lower part of the profile $(9-16 \mathrm{~cm}$ depth), the testate amoeba assemblage is dominated by Centropyxis cassis type and above $9 \mathrm{~cm}$ depth Arcella catinus type and Difflugia pristis

308 type are the most abundant taxa. Other more minor taxa occur throughout the profile, notably 309 other Centropyxis and Difflugia types, Cyphoderia ampulla, Corythion/Trinema types and 310 Tracheleuglypha dentata. All these taxa have been previously reported from this or other 311 North American marshes (Gehrels et al., 2006), with the exception of Campascus type, 312 previously only reported from the United Kingdom (Charman et al., 2000a).

313 With the exception of one sample, total test counts exceeded 50 for the nine 314 samples representing the $20^{\text {th }}$ century, and reconstructions based on transfer functions were 315 carried out on these samples (Figure 5). All the transfer functions suggest a generally rising 316 trend in sea level through the $20^{\text {th }}$ century. However, the uppermost samples suggest a 317 decline in reconstructed sea level, related to the appearance of small numbers of testate 
amoebae typical of very high marsh or freshwater conditions (e.g. Centropyxis arcelloides type, Trinema lineare type)) as well as a reduction in Difflugia pristis type (Figure 4). This is in opposition to the trends in the tide-gauge data which suggest a slight rise or flattening in sea level during this time. The local transfer function shows lower amplitude fluctuations during this period and the tolerance downweighted version of the transfer function also reduces the more extreme values. The bootstrapped error estimates for the testate amoebae are approximately two thirds of those for the foraminifera and the tide-gauge data fall within the estimated reconstruction errors for both testate amoebae and foraminifera based reconstructions, with the exception of the sample from the mid-1970s. This sample has consistently lower values for sea level but there were no foraminifera data available from the original counts made by Gehrels et al. (2002), so that it remains uncertain whether the deviation away from tide-gauge data is a result of problems with the testate amoebae data or

330 of some factor that affected the core location itself (such as localised freshwater ingress).

331 Excluding this sample, the estimated rates of sea-level rise vary between $1.62 \pm 0.17$ and

$3322.20 \pm 0.25 \mathrm{~mm} \mathrm{yr}^{-1}$ for the testate amoebae reconstructions, compared with $1.86 \pm 0.12 \mathrm{~mm}$

$333 \mathrm{yr}^{-1}$ for the tide-gauge data. Although there are a number of issues raised by the testate 334 amoebae data, clear conclusions are difficult given the relatively low sediment accumulation rate and low sample numbers resulting from this $\left(9\right.$ samples from the $20^{\text {th }}$ century for testate amoebae and only 5 for foraminifera).

\section{Chezzetcook}

339 Counts exceeding 50 tests were made down to $29 \mathrm{~cm}$ depth, with samples covering most of

340 the $20^{\text {th }}$ century (Gehrels et al., 2005). However, obtaining counts for some of these samples 341 required counting of multiple slides with considerable input of time. Concentrations are 342 similar to those at Wells with numbers up to 25,000 tests $\mathrm{g}^{-1}$, but often around $5-10,000$ tests $343 \mathrm{~g}^{-1}$ (Figure 6). The assemblages are dominated by Centropyxis cassis type and Arcella

344 catinus type with lower diversity of minor taxa than at Wells. C. platystoma type is more 
abundant towards the surface and Trigonopyxis arcula type is notable as a high marsh indicator for consistent occurrence in the deeper samples. each other. The tolerance downweighted model reduces the amplitude of change by only a small amount and the reconstruction based on the UK data is indistinguishable from the two

350 reconstructions based on North American data (Figure 7). The overall trend in the testate 351 amoebae reconstructions is very similar to changes inferred from foraminifera although the 352 gradient in the testate amoebae record is slightly steeper ( $3.70 \pm 0.61$ to $4.07 \pm 1.00 \mathrm{~mm} \mathrm{yr}^{-1}$ 353 compared to $\left.3.32 \pm 0.43 \mathrm{~mm} \mathrm{yr}^{-1}\right)$. The estimated errors for individual samples in both 354 records are very similar $( \pm 5 \mathrm{~cm})$. It is surprising that the errors are so similar, given that the testate amoebae reconstructions are based on data from sites ranging from other parts of the eastern North American coast and the United Kingdom. Whilst we would expect smaller errors for a location with a small tidal range, it is surprising that these very different approaches yield similar error estimates. Reconstructions are in reasonable agreement with

359 the tide-gauge record, which shows a linear trend of $3.3 \pm 0.11 \mathrm{~mm} \mathrm{yr}^{-1}$. Larger short-term fluctuations are shown by the foraminifera-based reconstruction than in the amoebae record.

361 While this may be partly due to the larger number of foraminifera samples analysed, the short-term decline in sea level at C. AD 1955 registered by the foraminifera is at least partly sampled but not reflected by the testate amoebae record. As this deflection is also not shown

364 by the tide-gauge record, it must be a result of changes only in foraminifera assemblages.

\section{Discussion}

\section{Test concentrations and preparation}

368 The data on testate amoebae presented here and other previous studies highlight the

369 problems of separating low numbers of testate amoebae from a matrix of similar size

370 particles (Roe et al., 2002). In contrast to terrestrial peat, tests are often present in relatively

371 low concentrations and are obscured by large amounts of silt-sized organic and inorganic

372 detritus. We have attempted to increase the range of samples that can be economically 
analysed by using a weak alkali treatment in preparation. This has been effective in

374 improving counts to statistically useful levels for the two cores presented here. While it is well

375 known that strong chemical pre-treatment such as that applied in pollen analysis can selectively destroy tests (Tolonen, 1986; Hendon and Charman, 1997), short periods in weak alkali (5\% $\mathrm{KOH}$ in this case) do not appear to have this effect. Although further work on a wider range of samples is still needed, the gains in analysis of salt-marsh sediments may outweigh any concerns over loss or damage to tests. Counting of salt-marsh samples is still more difficult than for many terrestrial peat samples and it takes considerable time (typically 0.5-1 day per sample) using multiple slide preparations to achieve counts $>50$ tests. Some samples will remain impossible to count to these levels, and on the basis of the data from Wells, this limit seems to be around concentrations of 1000 tests $\mathrm{g}^{-1}$. It is not surprising that fossil samples in these cores have relatively low concentrations because the cores are from the high marsh within the zone dominated by Balticammina pseudomacrescens and Jadammina macrescens, with low abundances of various other taxa (Gehrels et al., 2002, 2005). The Wells core is from $1.70 \mathrm{~m}$ NGVD which is in the lowermost zone of testate amoebae occurrence (Figure 2). Testate amoebae are most abundant and diverse above this zone (Charman, 1998; Gehrels et al., 2001) so the core location may be sub-optimal for testate amoebae populations. The Chezzetcook core is from just below HAT, so is in a better

391 position; this may be one of the reasons why the reconstruction for this site shows greater 392 agreement with the tide gauge record.

\section{Regional scale transfer functions}

395 The application of the UK training set to modern and fossil North American samples shows 396 that testate amoebae zonation is sufficiently consistent over large regions such as the North

397 Atlantic, to be able to use regional scale transfer functions successfully. Elevations estimated 398 for North American modern samples using the UK transfer function are surprisingly accurate 399 (Table 3, Figure 3). Reconstructions from fossil samples show very little difference with those 400 based on the North American transfer function (Figures 5 and 7). This is in contrast to 
401 foraminifera, where generally application is limited to local (Gehrels et al., 2001) or regional

402 (Horton et al., 1999b; Edwards et al., 2004) training sets. The wide geographical applicability

403 of the transfer functions suggests that they are more likely to be temporally robust than

404 transfer functions that only perform well in cross validation for single locations or small

405 regions. Whilst our data are still relatively few, these results indicate excellent potential for

406 developing large scale regional training sets in future work. Testing transfer functions by

407 application to other regions also reveals some of the problems with relying on cross-

408 validation statistics to evaluate model performance (Figure 3). Whilst extremely good

409 performance can sometimes be shown for some models such as the PLS model for the UK

410 data (Table 3), problems with systematic bias are clearly revealed when using them to

411 estimate elevations of independent samples with known elevations (Figure 3). It seems likely

412 that transfer functions that make use of residual variation in each iteration of the calibration

413 calculation (PLS, WAPLS) will be more susceptible to such problems.

\section{Precision and accuracy of reconstructions}

416 One of the main aims in pursuing work on testate amoebae in salt marshes is to improve 417 precision of palaeo-sea level estimates. However, more precise reconstructions must also be 418 demonstrably accurate. Estimated sample-specific errors in fossil samples derived from 419 bootstrapping of the models based on the modern North American data are around $\pm 5 \mathrm{~cm}$ for

420 Chezzetcook and $\pm 11 \mathrm{~cm}$ for Wells, the difference being due to the larger tidal range at

421 Wells. However, these error terms only include uncertainty in the relationship between

422 modern assemblages and measured elevation. They assume the relationship between fossil 423 assemblages and palaeo-elevation is the same, disregarding possible effects of changing 424 tidal regimes, disturbance, taphonomy, preservation and processing, and any other factors 425 that may have influenced the observed assemblage. Good agreement between proxies and 426 tide-gauge data in the Chezzetcook sequence suggests that these other effects are small at 427 least for the last 100 years, and thus we have greater confidence in the envelope of 428 uncertainty at this site (Figure 7). The agreement is less strong for the Wells site, although 
low sedimentation rates and consequently low sample resolution make clear conclusions

430 difficult here (Figure 5). The similarity of error estimates for the UK and North American

431 transfer functions also supports the idea that local site factors play only a relatively minor role

432 in determining testate amoebae assemblages.

434 An alternative approach to assessing precision is to calculate RMSEP values based on a 435 comparison between the reconstructed values and the tide gauge data. This yields more 436 realistic error estimates than those based purely on cross validation. In this case, the

437 RMSEP values are $6.7 \mathrm{~cm}$ for the Wells WAT reconstruction and $3.5 \mathrm{~cm}$ for the Chezzetcook 438 reconstruction. Surprisingly the RMSEP values for both cores are lower than the 439 bootstrapped RMSEP values suggesting the actual error is less than that estimated from the 440 transfer function alone, and supporting the idea that bootstrapped errors can be used as a 441 reasonable conservative estimate of the average actual error in reconstructions from the pre442 instrumental period. However, it is also clear that some individual samples can yield 443 reconstructed values that are clearly out of line with recorded variations and, if taken at face 444 value in the fossil record, would imply rapid short-term fluctuations in past sea level. Clearly 445 estimates of past sea-level change are more robust for multi-decadal to centennial trends 446 than they are for decadal fluctuations, even where sedimentation rates allow for such high 447 resolution reconstructions.

\section{Conclusion: Improving sea-level reconstructions from testate amoebae}

450 The cores used here for analysis were initially selected to optimise results from foraminiferal 451 analysis. They are within the most stable area of the high salt marsh within the narrow zone 452 dominated by Balticammina pseudomacrescens and other high marsh foraminifera. In this 453 zone foraminifera are abundant at the surface and down-core. However, testate amoebae 454 are most abundant and most clearly zoned in the very uppermost parts of salt marshes 455 (Charman et al., 2001; Gehrels et al., 2006). The fossil assemblages recovered in the two 456 cores presented here are indicative of the mid to lower zones of testate amoebae occurrence 
457 in marshes. There are very few of the taxa that are associated with higher locations on the 458 marsh, where zonation of assemblages is better defined because of rapid turnover of taxa 459 along the elevation gradient (Charman et al., 1998; 2002). Coring in locations at higher 460 elevations than would be used for foraminiferal analyses may yield more diverse faunas and 461 perhaps better constrained estimates of past sea levels. The setting of the highest part of the 462 marsh means that these zones are some of the best locations for sea-level reconstruction 463 because they are geomorphologically less dynamic than lower zones. Sedimentation rates 464 are likely to be stable, with continuous sediment accumulation over time. Thus, it is 465 particularly worthwhile pursuing proxy sea-level indicators such as testate amoebae in these 466 locations.

468 Despite the difficulties with small surface-training sets and sub-optimal core locations, the 469 Chezzetcook record shows that testate amoebae can be used to reconstruct past sea levels 470 with high precision and accuracy. The agreement with both foraminiferal reconstructions and 471 tide-gauge data shows that this technique is promising. The precision of the reconstructed 472 values is approximately $\pm 5 \mathrm{~cm}$ in this microtidal location as assessed by cross validation of 473 modern training sets and somewhat lower (RMSEP $3.5 \mathrm{~cm}$ ) when compared with tide gauge 474 data. This is similar or slightly better than the precision obtained from foraminifera, but this 475 level of precision is unusual for such studies. Furthermore, the testate amoebae data were 476 from a range of locations on the eastern North American coast and the United Kingdom, 477 suggesting testate amoebae are highly robust against local variations in the species478 environment relationships used to estimate past sea levels.

480 The nominal precision as estimated by cross validation in the Wells reconstruction is better 481 than that for foraminifera. This is likely due to the macrotidal location where foraminifera 482 zones are less tightly constrained. However, RMSEP values calculated from comparison with 483 the tide gauge records are slightly higher for testate amoebae than for foraminifera. If the 484 niches of testate amoebae taxa can be better constrained by further studies on surface 
samples so that the accuracy of estimates is improved, higher precision estimates of past sea-level change based on testate amoebae analysis will be possible at further sites. Future studies should retain multi-proxy indicators as a cross check on the accuracy of reconstructions, as well as utilising tide-gauge records alongside high resolution reconstructions to test reconstruction methodologies. Careful evaluation of transfer functions using approaches other than cross-validation of modern data sets is essential to avoid overestimating the ability of these techniques to reconstruct past changes from fossil samples. Comparison with tide gauge records provides a suitable means of achieving this.

\section{Acknowledgements}

This paper is a contribution to IGCP Project 495 ("Late Quaternary Land-Ocean Interactions: Driving Mechanisms and Coastal Responses") and to the North and West Europe working group of the INQUA commission on Coastal and Marine Processes. The paper benefitted from the comments of Antony Long and Edward Mitchell in review.

\section{References}

Belknap, D.F., Shipp, R.C., Stuckenrath, R., Kelley, J.T., Borns Jr., H.W., 1989. Holocene sea-level change in coastal Maine. In: Anderson, W.A., Borns Jr., H.W. (Eds.), Neotectonics of Maine.Maine Geological Survey Bulletin, Maine Vol. 40, pp. 85-105.

Bindoff N.L. et al., 2007. Observations: Oceanic Climate Change and Sea Level. In: Solomon, S., et al. (Eds.), Climate Change 2007: The Physical Science Basis. Contribution of Working Group I to the Fourth Assessment Report of the Intergovernmental Panel on Climate Change, pp. 385-432, Cambridge University Press.

Charman, D.J., Blundell, A., Chiverrell, R.C., Hendon, D., and Langdon, P.G., 2006. Compilation of non-annually resolved Holocene proxy climate records: stacked Holocene peatland palaeo-water table reconstructions from northern Britain. Quaternary Science Reviews 25, 336-350. 
513 Charman, D.J., Gehrels, W.R., and Roe, H. M., 2000a. The use of $<63 \mu \mathrm{m}$ fractions in the 514 separation and identification of testate amoebae in the inter-tidal zone, In: Hart, M.B., 515 Kaminski, M. A., and Smart, C. (Eds.), Proceedings of the Fifth International

Gehrels, W.R., 2000. Using foraminiferal transfer functions to produce high- resolution sea538 level records from salt-marsh deposits, Maine, USA. Holocene 10, 367-376. 
539 Gehrels, W.R., Belknap, D.F., Kelley, J.T., 1996. Integrated high-precision analyses of Holocene sea-level changes: lessons from the coast of Maine. Geological Society of America Bulletin 108, 1073-1088.

Gehrels, W.R., Belknap, D.F., Black, S., and Newnham, R.M., 2002. Rapid sea-level rise in the Gulf of Maine, USA, since AD 1800. Holocene 12, 383-389.

Gehrels, W.R., Milne, G.A., Kirby, J.R., Patterson, R.T., Belknap, D.F., 2004. Late Holocene sea-level changes and isostatic crustal movements in Atlantic Canada. Quaternary International 120, 79-89.

Gehrels, W.R., Kirby, J.R., Prokoph, A., Newnham, R.M., Achterberg, E.P., Evans, E.H., Black, S., Scott, D.B., 2005. Onset of recent rapid sea-level rise in the western Atlantic Ocean. Quaternary Science Reviews 24, 2083-2100.

Gehrels, W.R., Hendon, D., and Charman, D.J., 2006. Distribution of testate amoebae in salt marshes along the North American East Coast. Journal of Foraminiferal Research 36, 201-214.

Gehrels, W.R., Hayward, B.W., Newnham, R.M. and Southall, K.E., 2008. A 20th century sea-level acceleration in New Zealand. Geophysical Research Letters 35, L02717, doi 10.1029/2007GL032632.

Gehrels, W.R., Roe, H.M., and Charman, D.J., 2001. Foraminifera, testate amoebae and diatoms as sea-level indicators in UK saltmarshes: a quantitative multiproxy approach. Journal of Quaternary Science 16, 201-220.

Hendon, D. and Charman, D.J., 1997. The preparation of testate amoebae (Protozoa: Rhizopoda) samples from peat. Holocene 7, 199-205.

Holgate, S., 2007. On the decadal rates of sea-level change during the twentieth century. Geophysical Research Letters 34: L01602, doi:10.1029/2006GL028492.

Horton, B.P., Edwards, R.J. and Lloyd, J.M., 1999a. A foraminiferal based transfer function: Implications for sea-level studies. Journal of Foraminiferal Research 29, 117-129.

Horton, B.P., Edwards, R.J. and Lloyd, J.M., 1999b. UK intertidal foraminiferal distributions: implications for sea-level studies. Marine Micropaleontology 36, 205-223. 
Juggins, S. C2 User guide. Software for ecological and palaeoecological data analysis and visualisation. 2003. Newcastle upon Tyne, University of Newcastle.

Kelley, J.T., Gehrels, W.R., and Belknap, D.F. 1995. Late Holocene relative sea-level rise and the geological development of tidal marshes at Wells, Maine, U.S.A. Journal of Coastal Research 11, 136-153

Patterson, R.T., and Fishbein, E., 1989. Re-examination of the statistical methods used to determine the number of point counts needed for micropaleontological quantitative research: Journal of Paleontology, 63, 245-248.

Roe H.M., Charman D.J. and Gehrels W.R., 2002. Fossil testate amoebae in coastal deposits in the UK: implications for studies of sea-level change. Journal of Quaternary Science 17, 411-429.

Rose, N. 2002 Fly-ash particles. In: Last, W.M. and Smol, J.P., (Eds.) Tracking Environmental Change Using Lake Sediments. Developments in Paleoenvironmental Research 2: Physical and Geochemical Methods. Springer, New York, pp. 319-349.

Scott, D.B., 1977. Distribution and population dynamics of marsh-estuarine foraminifera with applications to relocating Holocene sea levels. Unpublished Ph.D. Thesis, Dalhousie University, Halifax, Nova Scotia, Canada.

Scott, D.B., Boyd, R., Medioli, F.S., 1987. Relative sea-level changes in Atlantic Canada: observed level and sedimentological changes vs. theoretical models. In: Nummedal, D., Pilkey Jr., O.H., Howard, J.D. (Eds.), Sea Level Fluctuation and Coastal Evolution. Society of Economic Paleontologists and Mineralogists Special Publication 41, pp. 87-96.

Scott, D.B., Suter, J.R. and Kosters, E., 1991. Marsh foraminifera and arcellaceans of the lower Mississippi Delta: controls on spatial distributions. Micropalaeontology 37, 37392.

Scott, D.B., Hasegawa, S., Saito, T., Ito, K. and Collins, E., 1995a: Marsh foraminiferal and vegetation distributions in Nemuro Bay wetland areas, eastern Hokkaido. Transactions and Proceedings of the Palaeontological Society of Japan 180, 282-95. 
595 Scott, D.B., Brown, K., Collins, E.S., Medioli, F.S., 1995b. A new sea level curve from Nova 596 Scotia: evidence for a rapid acceleration of sea-level rise in the late mid-Holocene. 597 Canadian Journal of Earth Sciences 32, 2071-2080.

598 Stockmarr, J., 1971. Tablets with spores used in absolute pollen analysis. Pollen et Spores $599 \quad 13,615-621$.

600 Tolonen, K., 1986. Rhizopod analysis. In: Berglund, B.E. (Ed.), Handbook of Holocene 601 palaeoecology and palaeohydrology, pp. 645-666.

602 van de Plassche, O., van der Borg, K., de Jong, A.F.M., 1998. Sea level-climate correlation 603 during the past 1400 yr. Geology 26, 319-322.

604 Varekamp, J.C., Thomas, E. and Van de Plassche, 0., 1992. Relative sea-level rise and 605 climate change over the last 1500 years. Terra Nova 4, 293-304.

606 Woodworth, P.L., White, N.J., Jevrejeva, S., Holgate, S.J., Church, J.A. and Gehrels, W.R., 607 2008. Evidence for the accelerations of sea level on multi-decade and century 608 timescales. International Journal of Climatology doi: 10.1002/joc.1771. 


\begin{tabular}{|c|c|c|c|c|c|c|c|c|c|c|c|c|c|}
\hline $\begin{array}{l}\text { Depth } \\
\text { (cm) }\end{array}$ & Count & T. lineare & C. dubium & D. pristis & D. pulex & D. type & P. fulva & C. Cassis & Cyphoderia & A. catinus & E.rotunda & Unknown & Total \\
\hline $8-9$ & 29 & 1.9 & & 7.8 & 3.9 & 11.7 & & & 1.9 & 27.2 & & 1.9 & 56.4 \\
\hline $16-17$ & 6 & & & & & & & 1.2 & & 4.6 & & 1.2 & 7.0 \\
\hline $24-25$ & 4 & & & 2.8 & & & 5.6 & 2.8 & & & & & 11.2 \\
\hline $31-32$ & 3 & & 6.0 & & & & & 6.0 & & & & 6.0 & 18.1 \\
\hline $40-41$ & 1 & & & & & & & & & & & 4.9 & 4.9 \\
\hline $48-49$ & 3 & & & & & & & & & 4.9 & & & 4.9 \\
\hline $57-58$ & 6 & & & & & 2.6 & 2.6 & & & 2.6 & & & 7.9 \\
\hline $65-66$ & 8 & & & & & 1.9 & & & & 5.7 & & & 7.6 \\
\hline Total & 60 & 1.9 & 6.0 & 10.6 & 3.9 & 16.2 & 8.2 & 10.0 & 1.9 & 45.1 & 0.0 & 14.0 & 117.9 \\
\hline
\end{tabular}

\begin{tabular}{|c|c|c|c|c|c|c|c|c|c|c|c|c|c|}
\hline $\begin{array}{l}5 \% \mathrm{KOH} \\
\text { Depth } \\
(\mathrm{cm})\end{array}$ & Count & T. lineare & C. dubium & D. pristis & D. pulex & D. type & P. fulva & C. Cassis & Cyphoderia & A. catinus & E.rotunda & Unknown & Total \\
\hline $8-9$ & 41 & & & 23.3 & 5.8 & & & & 5.8 & 44.7 & & & 79.7 \\
\hline $16-17$ & 13 & & & 4.6 & & & & & 3.5 & 7.0 & & & 15.1 \\
\hline $24-25$ & 12 & & & 8.4 & & 2.8 & & 8.4 & & & 8.4 & 5.6 & 33.5 \\
\hline $31-32$ & 4 & 6.0 & & & & 12.1 & & & & & & 6.0 & 24.2 \\
\hline $40-41$ & 0 & & & & & & & & & & & & \\
\hline $48-49$ & 0 & & & & & & & & & & & & \\
\hline $57-58$ & 1 & & & & & & 1.3 & & & & & & 1.3 \\
\hline $65-66$ & 0 & & & & & & & & & & & & \\
\hline Total & 71 & 6.0 & 0.0 & 36.3 & 5.8 & 14.9 & 1.3 & 8.4 & 9.3 & 51.7 & 8.4 & 11.6 & 153.7 \\
\hline
\end{tabular}

Table 1: Testate amoebae counts from standard (upper) and $\mathrm{KOH}$-based (lower) sample pre-treatment for eight samples from the Wells core. Total no.tests counted in left hand column. All other figures are concentrations (nos. $\mathrm{mg}^{-1}$ wet weight sample). 


\begin{tabular}{lllll}
\hline Model & $\mathrm{r}^{2}$ & Average bias & Max. bias & RMSEP \\
\hline WA_Inv & 0.84 & -0.0027 & 0.104 & 0.053 \\
WA_Cla & 0.85 & -0.0034 & 0.084 & 0.054 \\
WAT_Inv & 0.80 & -0.0047 & 0.123 & 0.059 \\
WAT_Cla & 0.81 & -0.0055 & 0.099 & 0.060 \\
PLS & 0.81 & -0.0011 & 0.095 & 0.057 \\
MAT & 0.78 & -0.0173 & 0.166 & 0.068 \\
WMAT & 0.80 & -0.0120 & 0.124 & 0.061 \\
\hline
\end{tabular}

Table 2: Transfer function performance in cross validation using the leave one out (jackknifing) method for the North American testate amoebae data. Results of WAPLS were the same as for simple weighted averaging and are not shown here. RMSEP (Root mean squared error of prediction) and bias data are for elevation normalised to the difference between mean tide level and highest astronomical tide. 


\begin{tabular}{lll}
\hline Model and application & $\mathbf{r}^{2}$ & RMSEP \\
\hline a) Cross validation & 0.41 & 0.076 \\
WA_Inv (Weighted average, inverse deshrinking) & 0.43 & 0.098 \\
WA_Cla (Weighted average, classical deshrinking) & 0.45 & 0.074 \\
WAT_Inv (Tolerance downweighted weighted average, inverse deshrinking) & 0.47 & 0.104 \\
WAT_Cla (Tolerance downweighted weighted average, classical deshrinking) & 0.42 & 0.077 \\
WAPLS Component 3 (Weighted average partial least squares) & 0.99 & 0.012 \\
PLS Component 5 (Partial least squares) & 0.44 & 0.074 \\
MAT (Modern analogue) & 0.61 & 0.063 \\
WMAT (Weighted modern analogue) & & \\
& & \\
b) Applied to US data & & \\
WAT_Inv & & \\
PLS Component 5 & & 0.083 \\
\hline
\end{tabular}

Table 3: Model performance results for the UK testate amoebae data; a) in cross validation using normalised (MTL-HAT) data, b) applied to normalised modern US data. , c) applied to actual elevation above MTL for individual sites. For b) and c), the RMSEP is calculated on the errors between the observed and predicted values shown in Figure 3, not on the linear trend lines shown. 


\section{Figure captions}

Figure 1: Locations for the core sites. See Gehrels et al. (2006) and Charman et al. (2002) for details of modern sampling sites.

Figure 2: Modern testate amoebae data plotted against elevation from the marshes used in the North American transfer function. a) Little River marsh, Wells, Maine, b) Little Dipper Harbour Marsh, New Brunswick. The tidal data shown on the height axis are highest astronomical tide (HAT) and mean highest high water (MHHW). HF is the maximum height of foraminifera recorded in the $63-500 \mu \mathrm{m}$ size range. .

Figure 3: Comparison between observed sample elevations for the modern North American samples and their predicted elevations based on the UK transfer function applied to the testate amoebae assemblages. a) For all samples plotted as elevation normalised for tidal range (MTL-HAT). b) and c) For untransformed elevations in height above MTL, b) Little River and c) Little Dipper Harbour. Circles - Little River, Squares - Little Dipper, Open - PLS model, Closed - WAT model. Linear regression lines shown as black (Little River) and grey (Little Dipper). Grey dashed line - 1:1 line.

Figure 4: Testate amoebae diagram for core FS-1, Wells, showing all samples, including those with low total counts. A further sample at $22.5 \mathrm{~cm}$ contained no testate amoebae or foraminifera. The estimated ages are shown with $2 \sigma$ errors based on ${ }^{210} \mathrm{~Pb}$ analyses.

Figure 5: Comparison between reconstructions for the Wells core based on testate amoebae, foraminifera and the tide gauge record from Portland, Maine (grey symbols). The rates of sea-level change are the linear trends over the period covered by the tide-gauge record. The rates for testate amoebae exclude the sample from the mid-1970s which gives consistently 
lower values and is not represented in the foraminifera samples. For comparison, the linear trend of the tide-gauge record is $1.86 \pm 0.12 \mathrm{~mm} \mathrm{yr}^{-1}$. Vertical error bars are RMSEP from transfer functions. Age error bars are $2 \sigma$ errors from age-depth model. No RMSEP values calculated for $c)$ because of the low number of samples $(n=17)$ in the local training set.

Figure 6: Testate amoebae \% diagram from Chezzetcook core CZ-25.

Figure 7: Sea level reconstructions based on testate amoebae and foraminifera from Chezzetcook Marsh compared to the tide gauge record from Halifax (grey symbols). The rates of sea-level change are the linear trends over the period covered by the tide-gauge record. For comparison, the linear trend of the tide-gauge record is $3.30 \pm 0.11 \mathrm{~mm} \mathrm{yr}^{-1}$. Vertical error bars are RMSEP from transfer functions. Age error bars are $2 \sigma$ errors from age-depth model. 


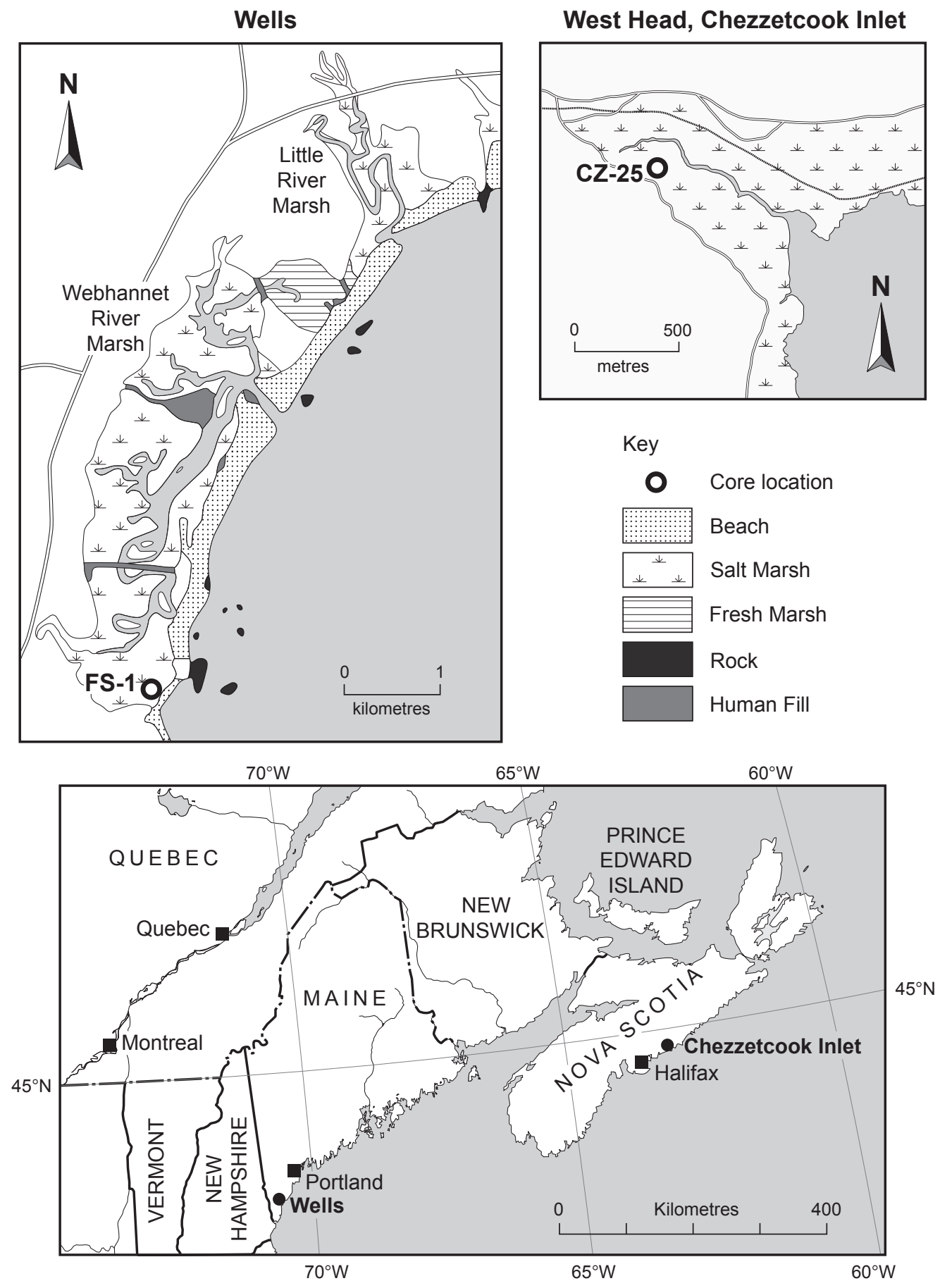


a)

Little River marsh, Wells, Maine

Testate amoebae

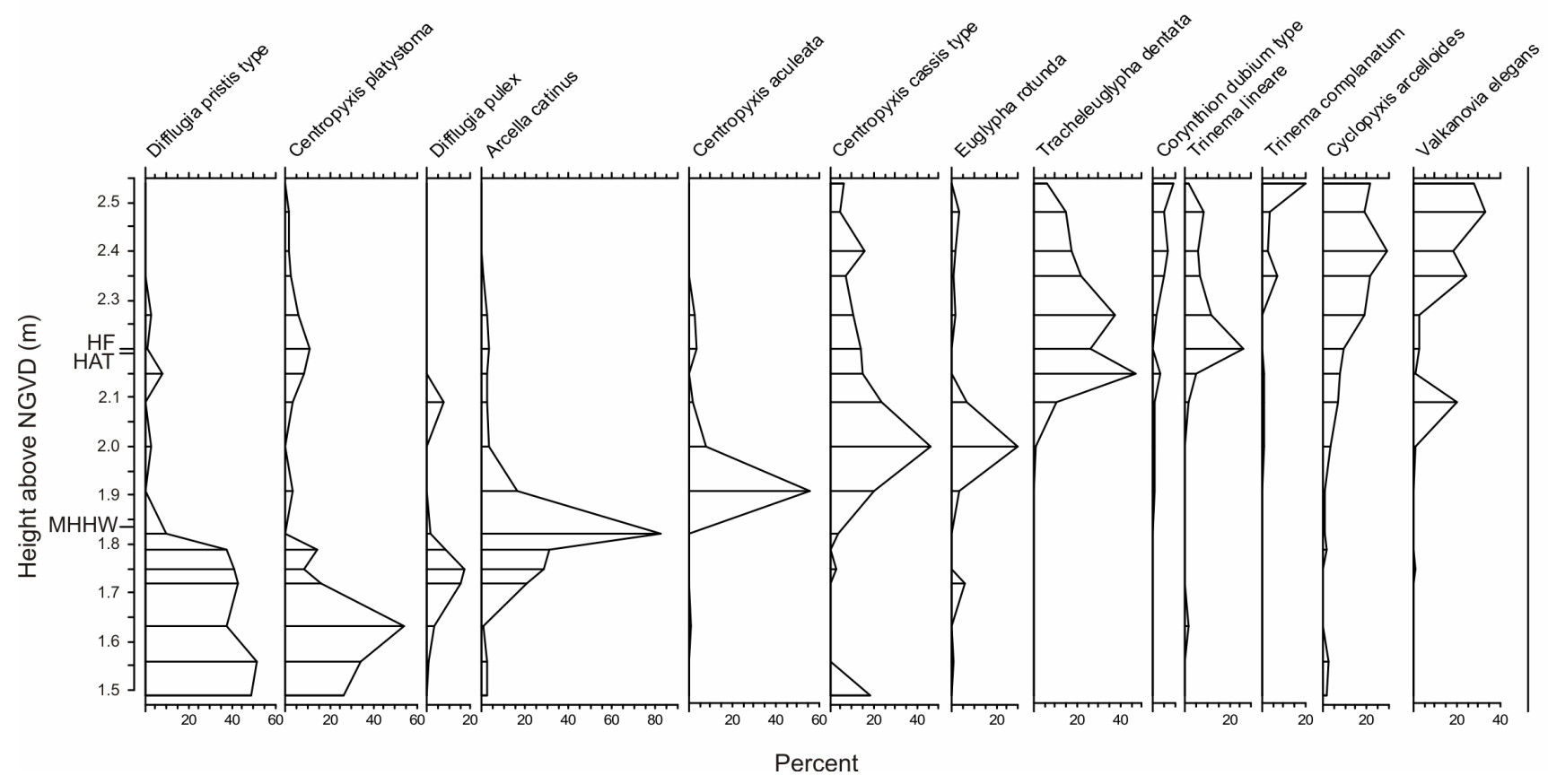

b)

Little Dipper Harbour marsh, New Brunswick

Testate amoebae

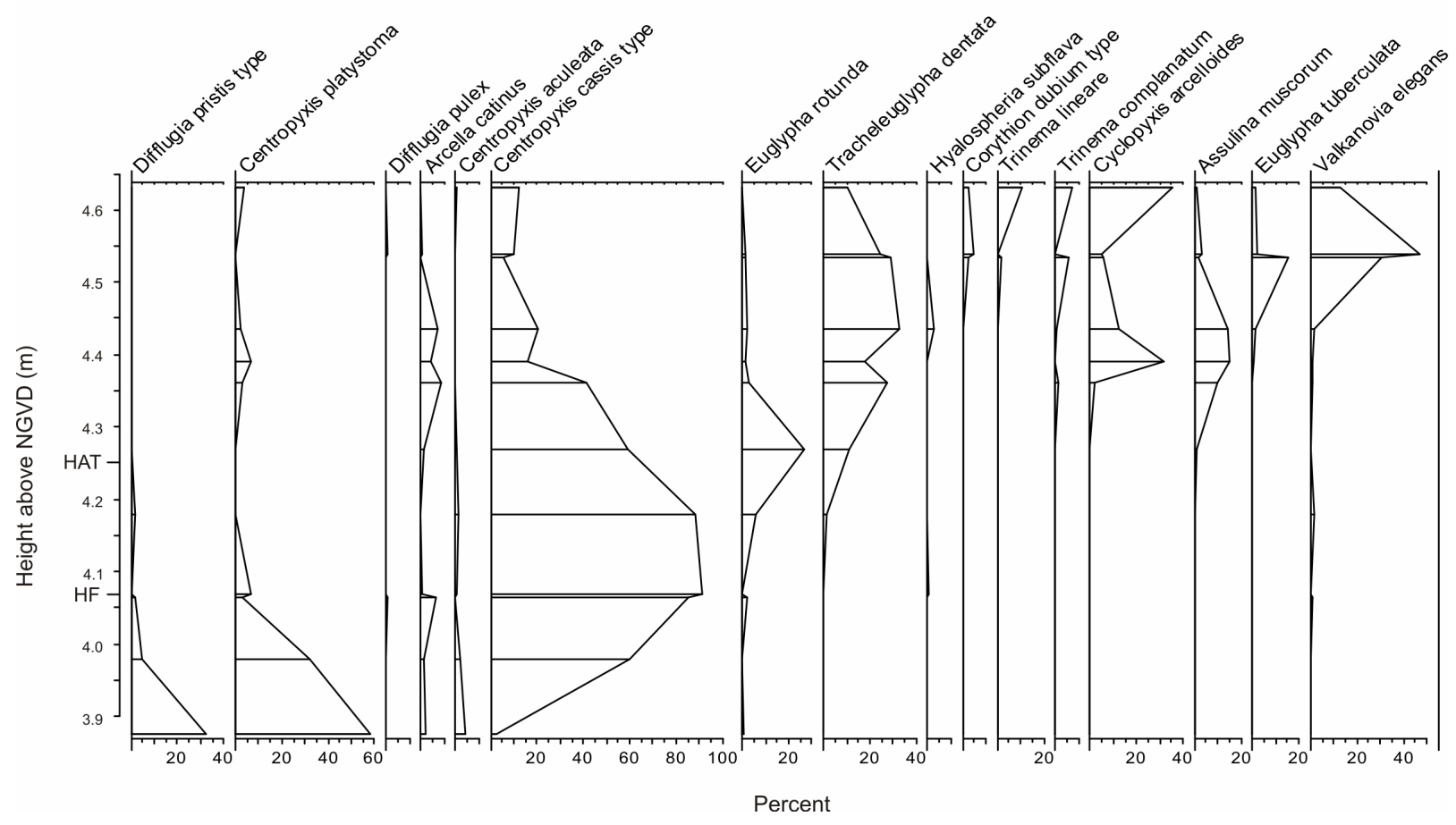


a)

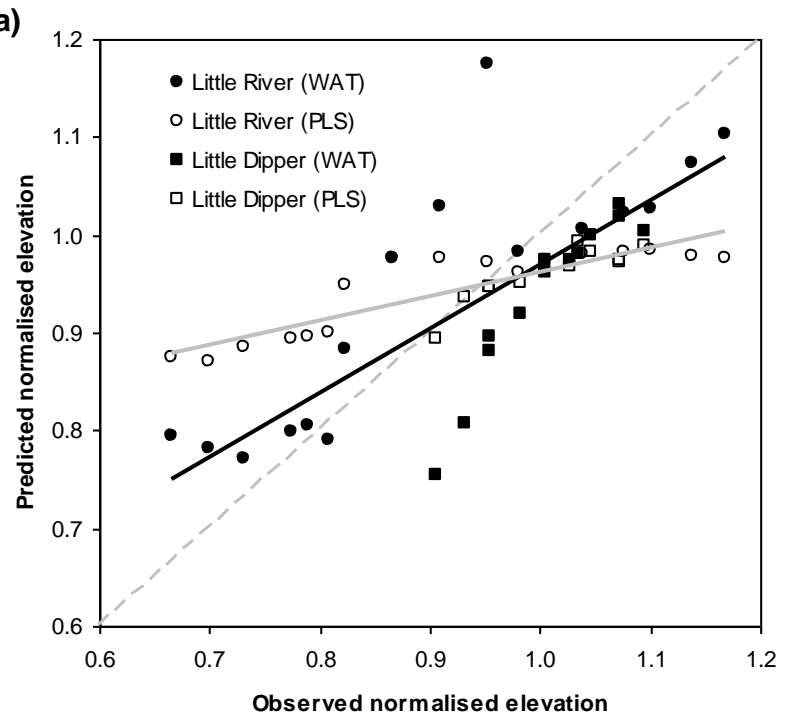

b)

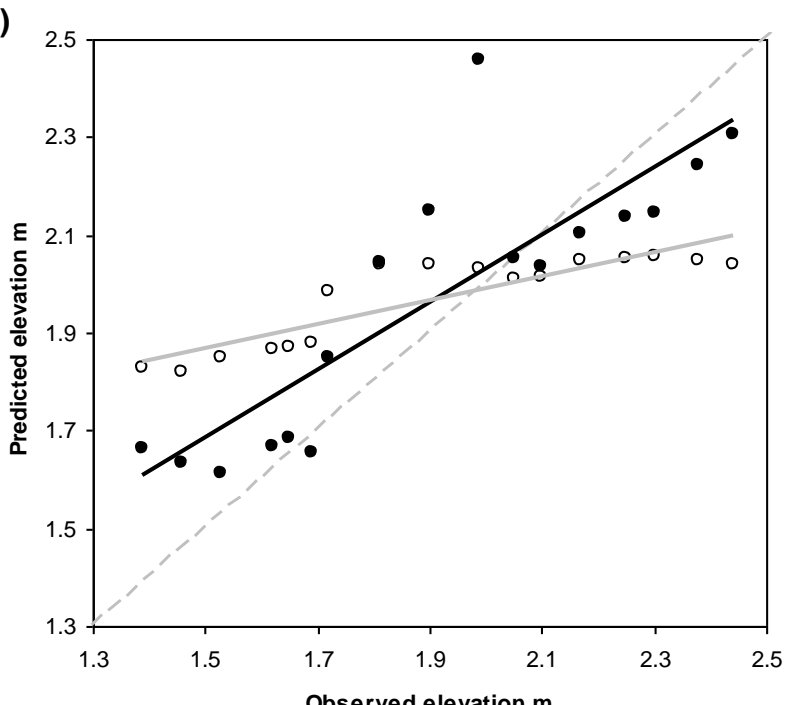

c)

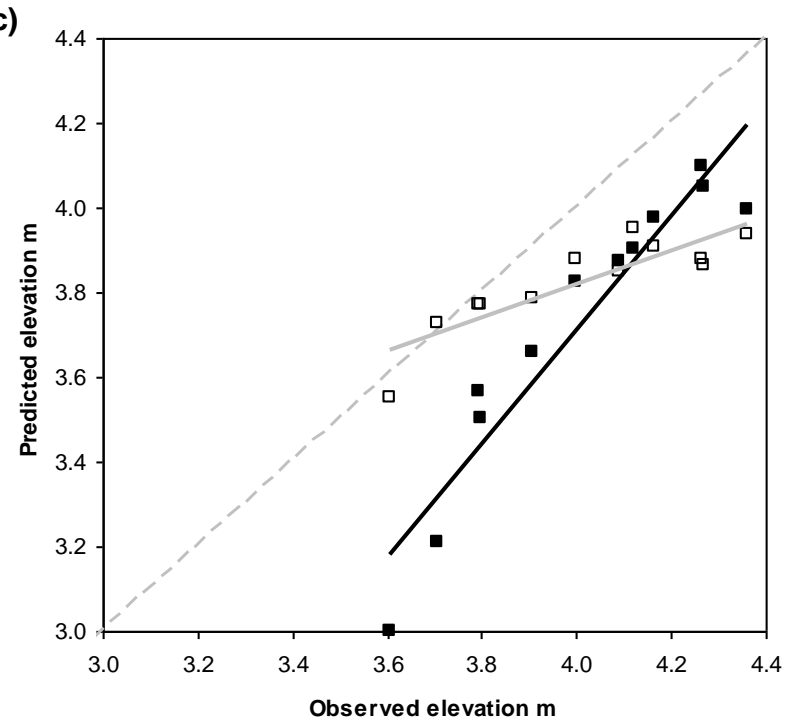




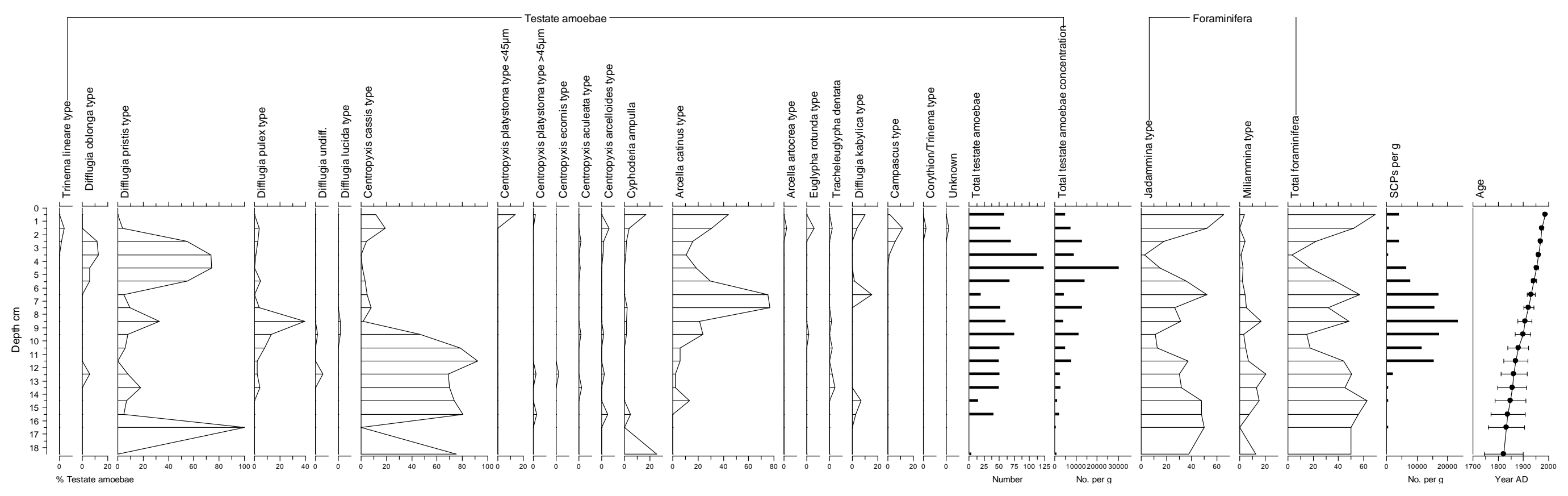




\section{Figure 5}

Click here to download Figure: Figure 5.pdf
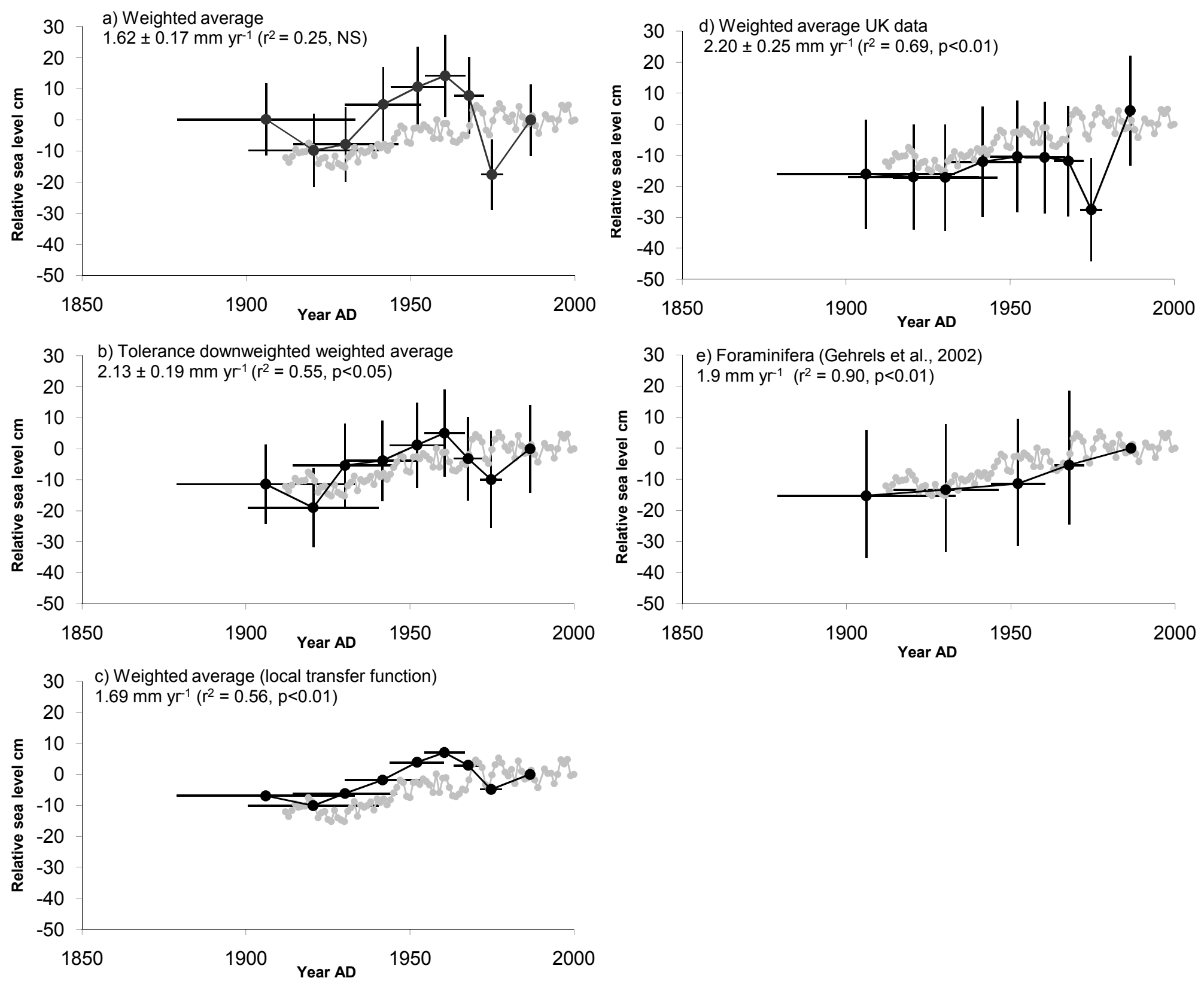


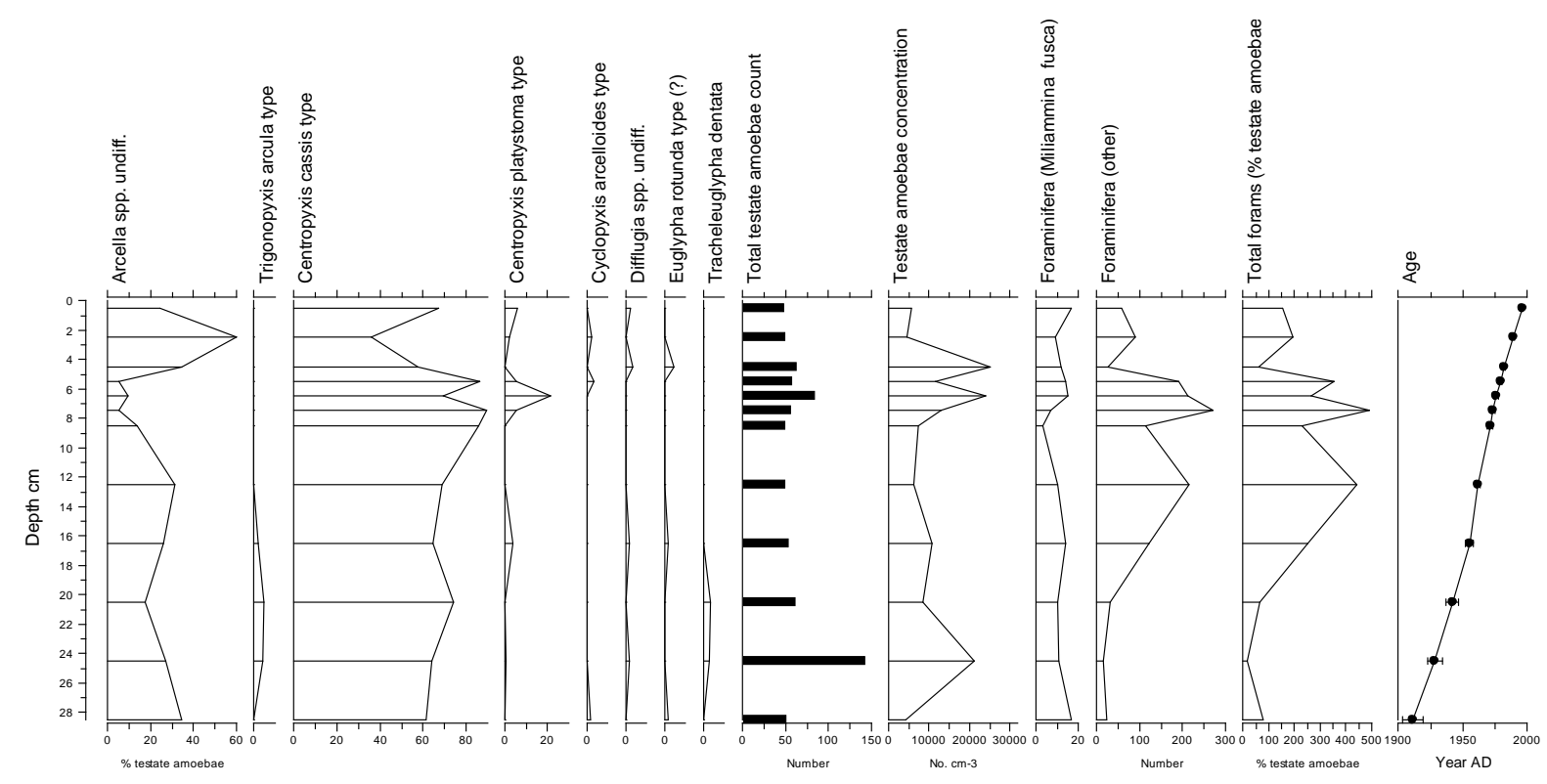




\section{Figure 7}

Click here to download Figure: Figure 7.pdf
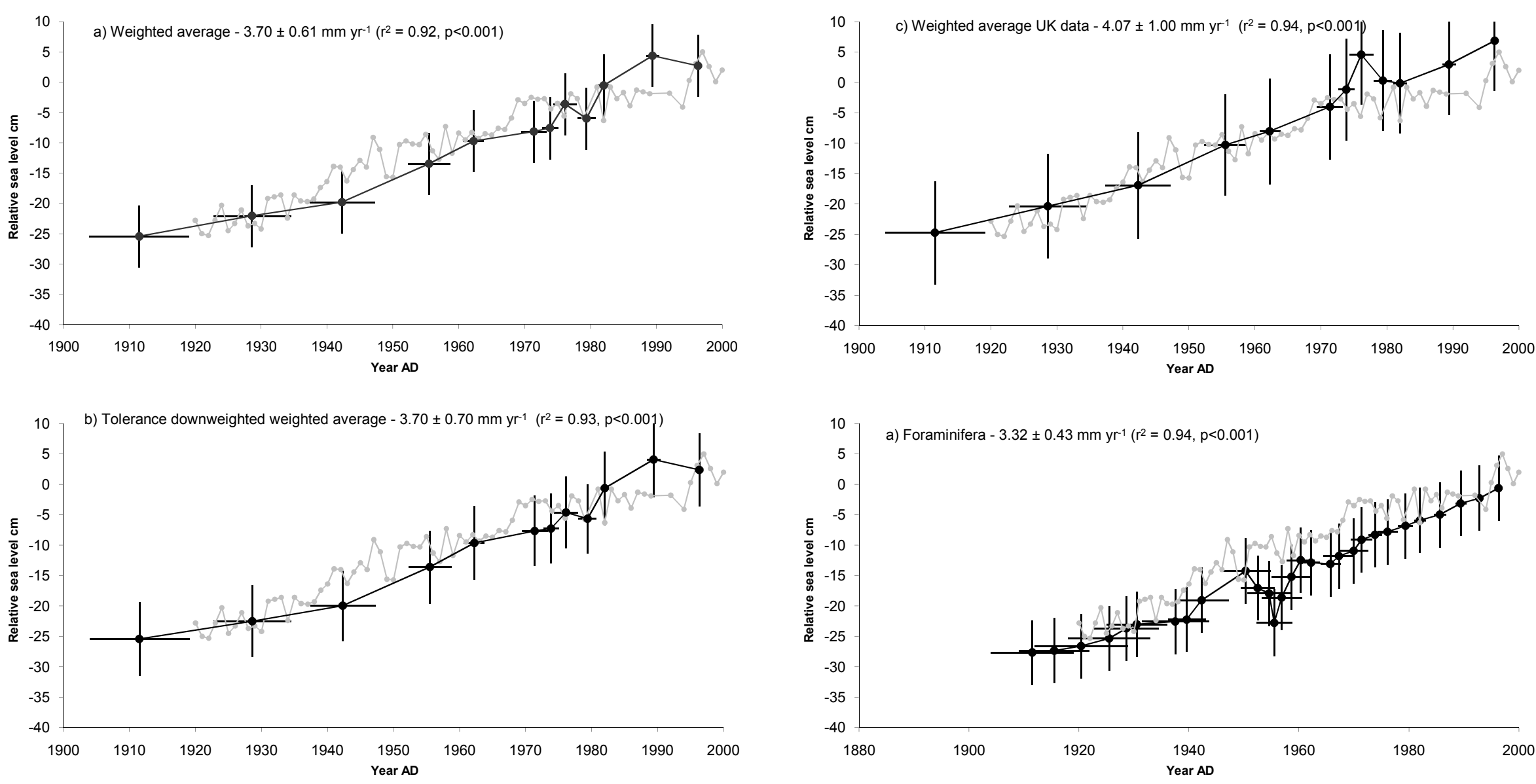